\title{
An Empirical Study on the Application of Lexical Chunk to College English Writing
}

\author{
Qian Li \\ Foreign Languages Department of Shandong Jiaotong University, Jinan, China
}

\begin{abstract}
In China, English, as an important tool for self-expression and mutual communication, is paid great attention to all over the country and College English has become a compulsory course at all colleges and universities. English writing is one of the most important language skills for college students. For a long time, English writing has been the throe throat for college students, which manifests in the aspects that students have poor vocabulary and employ much Chinglish expression in their essays, hindering them from expressing themselves clearly. Many linguists and teachers have been doing research on foreign language teaching, trying to find an effective way to improve the students' foreign language acquisition especially foreign language writing. And thus the approach of employing the lexical chunks to teaching was put forward. The approach of teaching English writing by chunks offers a new way of solving the problems. Based on the previous research, the author thinks it necessary to probe into teaching English writing by lexical chunks so as to improve students' writing ability. This study increases the input of English Lexical Chunk to College English writing and analyzes the effect of this method on students' writing by conducting experimental research. According to the experiment analysis, it is concluded that increase of Lexical Chunk input can reduce the negative transfer of the native language, thus improving their writing in terms of wording collocation, sentence building, discourse cohesion and expression.
\end{abstract}

Index Terms - lexical chunk, college English writing, empirical study

\section{INTRODUCTION}

Nowadays, with economic development and cultural globalization, English has become an important tool for self-expression and mutual communication. In China English education is paid great attention to all over the country and College English has become a compulsory course at all colleges and universities. English writing is one of the most important language skills for college students. Though English writing is an important language skill to students, in the schools and universities the teaching of writing lays emphasis on the English vocabulary, grammar and structure, paying less attention to the practice of writing as a whole including the process of planning, generating and the organization. The present situation that the teachers ignore the English writing has caused the students' lack of motivation and interest in writing. For a long time, English writing has been the throe throat for college students, Even though they can memorize a large number of new words, there still exist some problems in the process of transferring from language input to language output. Their essays lack the effective organization and thus lead to the incoherence and inconsistency of expressions and even employing much Chinglish expression in their essays, hindering them from expressing themselves clearly.

Many linguists and teachers have been doing research on foreign language teaching, trying to find an effective way to improve the students' foreign language acquisition especially foreign language writing. And thus the approach of employing the lexical chunks to teaching was put forward. The approach of teaching English writing by chunks offers a new way of solving the problems.

Lexical chunks usually refer to frequently-occurred, fixed or semi-fixed multi-words or sentences formed by meanings rather than grammatical rules that are acquired as a whole automatically in the language acquisition. Lexical chunks approach is based on the idea that language is made up of grammatical lexis instead of lexicalized grammar. Many experts and educators have been doing research on lexical chunks, finding that chunks play an important role in our everyday communication, making contributions to the ease, accuracy and fluency in listening, speaking, reading and writing. What's more, lexical chunks are an effective way to improve students' English writing in the foreign language acquisition.

Based on the previous research, the author thinks it necessary to probe into teaching English writing by lexical chunks so as to improve students' writing ability.

In this study, writing refers to school composition writing. A school composition is a short writing, which is also called an essay. The general goal of English writing at an elementary level set for college non-English majors in College English Syllabus is to write a composition of about 120 to 150 words within thirty minutes on a given topic or outline; Express themselves clearly without critical language errors.

This study increases the input of English Lexical chunk to College English writing and analyzes the effect of this method on students' writing by conducting experimental research. In order to classify the effects of lexical chunks on English writing, the author carried out the experiment in two classes with the same level in the Shandong Jiaotong 
University. During the experiment, the author employed the traditional way to English writing in the control class. Meanwhile, the increase of input of lexical chunks to English writing was applied to the experiment class. During the experiment, the subjects in the two classes were asked to take pre-test and post-test. After the experiment, the author analyzes the result of the two tests to find the effects of lexical chunks on English writing.

Based on the experiment analysis, it is concluded that increase of Lexical Chunk input can reduce the negative transfer of the native language, thus improving their writing in terms of wording collocation, sentence building, discourse cohesion and expressiveness.

\section{LITERATURE REVIEW}

\section{A. Definitions of Lexical Chunks}

During the late age of the nineteen century, there has been an increasing concern about the linguistic study in China and abroad. Many linguists, scholars and teachers devote themselves to the language teaching and acquisition and some new approaches have been employed to foreign language teaching and learning. Among these approaches, input of Lexical Chunks have been advocated and employed to the language acquisition. There have been different definitions of Lexical Chunks. Becker (1975) first put forward his opinion that lexical chunks are these particular multi-words or sentences, which are usually in the form of fixed or semi-fixed chunks and share the common characteristics of traditional grammar and lexis. And, Nattinger \& Decarrico (1992), who also defines Lexical Chunks as "multi-word lexical phenomena", arguing that these chunks are ready-made multi-word expressions, "They are similar to lexicon in being treated as units, yet most of them consist of more than one word, and many of them can, at the same time, be derived from the regular rules of syntax, just like other sentences". They think that these phrases are "collocations that are assigned pragmatic functions", which differs them from other multi-word units like idioms or collocations.

In The Encyclopedia of Language and Linguistic (Volum3), lexical chunks are defined as "a cover term for ready-made constructions which can be used without having to be built up from scratch."

Pawley and Syder (1983) defined that lexical chunk is "a unit of clause length or longer whose grammatical form and lexical content is wholly or largely fixed".

Lewis (1993) holds the opinion that the basis of language learning is lexis, thus regarding the lexical chunks as "the building blocks of language learning and communication not grammar, functions, notions or some other unit of planning and teaching but lexis, that is, words and word combinations."

Regina Weinert (1995) does research on the lexical chunks and see them as "multi-word (How are you doing?) or multi-form strings (called; haven't) which are produced or recalled as a whole chunk, much like an individual lexical item, rather than being generated from individual lexical items/forms with linguistic rules." n(Sun Huamei, 2010)

Moon gives his definition that lexical chunks are "a vocabulary item which consists of a sequence of two or more words (a word being simply an orthographic unit)" (Moon, 1997, p.43). According to his opinion, these words are combined according to the whole meaning rather than grammatical rules.

Janet Hooper, Florence Myles and Rosamond Mitchell (1998) argue that lexical chunks are rote-learned word groups or imitated chunks of unanalyzed language.

By analyzing these definitions of the scholars and linguists above, the author holds an opinion that lexical chunks are frequently-occurred, fixed or semi-fixed multi-words or sentences formed by meanings rather than grammatical rules that are acquired as a whole automatically.

\section{B. Classifications of Lexical Chunks}

From the introduction above, it is known that many linguists have been trying to give a definition of lexical chunks. In addition to the definition, some of them also attempt to classify lexical chunks from different perspectives and aspects so as to employ them to language teaching and acquisition well.

Richard J. Alexander (1984) classifies lexical chunks from the perspective of formal degree and function and divides them into idioms, discourse, proverbs, catchphrases as well as quotations and allusions.

Nattinger \& Decarrico (1992), divides lexical chunks into four categories: polywords, institutionalized expressions, phrasal constraints and sentence builders.

Moon (1997) argues that lexical chunks consist of five kinds of items: compounds, verbs, idioms, fixed phrases and prefabs or ready-made units.

Lewis (1997) identifies four basic groups of lexical items: words and polywords, collocations, institutionalized utterance frames and heads.

\section{Related Studies at Home and Abroad}

Since the definition of lexical chunks were put forward, the research on them have been more than theory. Many linguists have been employing them to the language acquisition and have been analyzing by experiment what effects the lexical chunks have on language learning and acquisition.

In the 1970s, Becker (1975) was one of the first to suggest the importance of the lexical phrases to our idea expression. He held the opinion that we used "ready-made frameworks on which to hang the expression of our ideas."

Michael Lewis employs lexical chunks approach to teaching, writing the masterpieces with the titles The Lexical 
Approach and Implementing the Lexical Approach. Lewis (1993) argues that "Language consists of grammatical lexis - not lexicalized grammar," and lexical chunks, as a kind of grammatical lexis play a vital role in language acquisition in all aspects of listening, speaking, reading and writing.

Nattinger\&Decarrico (1992), do research on the lexical phrase, trying to find if this unit can serve as an effective basic unit for second language or foreign language teaching. They do experiments to examine the ways that lexical phrases are organized in different kinds of written discourse, among which three kinds of EFL writing are selected including the formal essay, the informal letter and the business letter. By analyzing the research, they conclude that the input of these lexical phrases can help the EFL learners to express themselves well in the writing.

In China, there also exist researchers who have carried out experimental studies on lexical chunks. Wu Jing and Wang Ruidong (2002) do an experimental study on lexical chunks, in their study they made a survey of foreign studies on lexical chunks trying to advocate readers to focus their attention on the functions and advantages of lexical chunks.

Yao Baoliang (2003) does research on the lexical chunk in the middle school, writing, discussing the function of prefabricated language and the way of applying prefabricated language to spoken English (Some researchers call lexical chunks as prefabricated language).

Duan Shiping (2008) reviews the studies on lexical chunk in the second language acquisition at home and abroad in the past 10 years, including the definition and distinctive features of lexical chunk, the focus of research on lexical chunk and different perspectives and research approaches.

In all, many researchers and scholars home and abroad have realized the importance of lexical chunks in foreign or second language teaching and learning, carrying out experimental research to verify the positive effects of chunks on students' language learning and acquisition.

\section{Methodology}

In the chapter above, the author reviews the definition and classification of the lexical chunks as well as the related studies at home and abroad, which provided the theoretical and experimental basis for this thesis. In this chapter, the empirical study is listed, which aims to describe how to apply lexical chunks to improve students' writing. The research question, subjects, instrument, procedures, result and discussion in the writing training are included here.

\section{A. Research Question}

This study attempts to find whether there exist some effects on the college students' English writing by increasing the input of lexical chunks in two classes of Shandong Jiaotong Univertity. Therefore the research question is whether application of lexical chunk approach to EFL teaching helps to improve college students' EFL writing level.

\section{B. Subjects}

The students who participate in this study are the freshmen of Shandong Jiaotong University majoring in Vehicle Engineering. They have just finished senior middle school study and passed the Entrance Examination to College. It is the first term for them to have English classes in this college according to the curriculum requirement of the university authority. They are very curious, cooperative, which helped the researcher to carry out the experiment. They are taught by the author with the same textbook, which is New Horizon College English published by Foreign Language Teaching and Researching Press. They have the same class time with the same English teacher. In order to get to know the participants' initial knowledge and select the participants who are at the same level, the researcher designed the pretest at the beginning of the term. After the pretest, the students were ranked according to their pretest scores and divided into two classes. Class 1 of forty students is selected to be experimental group (EG), and Class 2 of 40 students is control group (CG). The two classes are at approximately equivalent level of English writing at the beginning of the experiment.

\section{Instruments}

\section{Pretest}

In order to get to know the participants' initial knowledge and select the participants who are at approximately equivalent level, the researcher designed the pretest at the beginning of the term, during the test the students were allowed to write a composition on the same topic and outline given in Chinese in thirty minutes. They should write at least 120 words, the topic was chosen from College Entrance Examination which is regarded as the most influential Chinese national English to measure the high school students' English proficiency. The pretest was carried out in class in the supervision of the teacher so as to make sure that the students do it by themselves. After the test, all the compositions were collected and graded by the two English teachers according to the same criteria. The average scores between the teachers were the ultimate scores. And then their scores were collected and analyzed.

2. Post-test

In order to see whether there was any improvement made by the students attended the experimental or not, the posttest is designed at the end of the term. After the pre-test, the author provided the students more opportunities for them to observe the lexical chunks appearing in the textbook and various exercises were employed to strengthen their awareness of lexical chunks. During the period, the practice of lexical chunks was prepared and the writing instruction 
mainly focused on the input of chunks. In the posttest the students were also allowed to write a composition on the same topic and outline given in Chinese in thirty minutes as the pretest. The whole process of test was supervised under the teacher. After the test, all the compositions were collected and graded by the two English teachers according to the same criteria. The average scores between the teachers were the ultimate scores. After the test, scores of the two classes were collected and analyzed and then the two results were compared to each other so that to find whether there did exist significant improvement of the students' writing skills after one-term training.

\section{Procedure}

The experiment lasted one term for 14 weeks. The steps of the experiment were as follows:

Both groups had the same English class based on the procedures suggested in the textbook every week. The new words and expressions in the book were taught in the class for both groups. The experimental group received extra lexical chunks instruction from the beginning of the term while the control experiment didn't. The author laid emphasis on the selection, acquisition and application of multi-word chunks instead of single words without the definite context. The training involved four steps:

1. Preparation

In this step, the teacher explained to the students that lexical chunks usually refer to frequently-occurred, fixed or semi-fixed multi-words or sentences formed by meanings rather than grammatical rules that are acquired as a whole automatically in the language acquisition. And the multi-word chunks are different from common vocabulary, phrases and sentences in the aspect that lexical chunks are ready-made, meaning-based and can be treated as a whole. Besides, mufti-word chunks play an important role in the ease, accuracy and fluency of ELF writing. In the class the examples of lexical chunks formed by 2-7 word are introduced to students to help them know the typical characters of the lexical chunks

\section{Presentation}

This step is about the teaching procedures in which the input of lexical chunks is increased to English teaching. At the beginning of every English class, about fifteen minutes were set aside for four or five students for spot-check. After choosing chunks in the text, the whole class students were encouraged to pick out the chunks they met in the texts according to their understanding by themselves, and then the author checked what the students had selected and gave some corrections if some mistakes appeared.

3. Practice

In this step, students are provided with the opportunity to practice the mufti-word chunks that have been learned in the class teaching. They were first asked to remember these chosen lexical chunks and then make effort to use mufti-word chunks in real communicative tasks to reinforce their understanding and memorizing of chunks. The teacher provided some contextual information to help the students practice some particular mufti-word chunks. In the next class, the teacher will check students whether they have memorized the lexical chunks by dictation or word-filling in the passage. Meanwhile, the author should show the students the basic outline of written discourse so that they could learn how to build sentences and construct the framework of a passage.

4. Evaluation

After the practice of lexical chunks, the performance of the students was checked and evaluated. The main purpose of this step was to provide students with opportunities to evaluate their own achievement in using these useful mufti-word chunks, thus developing their chunk awareness in their own learning processes.

The students are required to write an essay concerning the topic in their textbook every week and encouraged to use the lexical chunks they have learnt in their essays. After marking their essays, the teacher comments on their writing and chooses the excellent ones to display in class, especially praise them on their appropriate use of lexical chunks so as to be the models for all the students to follow. In this way, the students' practice of lexical chunks is strengthened.

\section{E. Results and Discussions}

At the end of the term, all the students in EG and in CG took the same writing tests. After the tests, the papers are collected and marked. To achieve the highly objectiveness of the scoring of composition, the researcher and his colleague will give a grade on each student's writing pretest and posttest. If the differences in scores are within 4 scores, the average of the two score will be the eventual one, otherwise, the two raters will discuss together to give the student an appropriate score.

1. Results and Discussions of the Pre-test.

At the beginning of the experiment, the pre-test writing is presented among the 40 non-English major students to see whether there was a significant difference between the experiment class and the control class concerning their writing competence. The results of the pre-test are analyzed by a statistical analysis system (SPSS 12.0). Then their mean scores and standard deviations are to identify the differences of the two classes in writing.

TABLE1

PRETEST ANALYSIS OF CLASS 1 AND CLASS 2

\begin{tabular}{|l|l|l|l|l|l|}
\hline group & Mean & $\mathrm{N}$ & Std. Deviation & Std. Error Mean & Sig. (2-tailed) \\
\hline CLASS1 & 64.9000 & 40 & 13.41029 & 2.12035 & \\
\hline CLASS2 & 64.9500 & 40 & 11.05916 & 1.74861 & .985 \\
\hline
\end{tabular}


From the table 1 above, it can be found that before the experiment, the mean of the experiment class as 64.90 and S.D.13.41029, while those of the control class as 64.95 and 11.05916 respectively. The descriptive statistics show that for the two groups the means are nearly the same. So it is easy to make a conclusion that the students in two classes have the approximately equal English proficiency.

From the paired sample test, sig $=0.985>0.05$, it can be concluded the difference between the two classes is not significant. There is no difference in English proficiency between the students in two classes. This result may ensure that by the end of the experiment, the change in the scores of their writing mainly is caused by the employment of new teaching approach to teaching rather than other factors.

2. Results and Discussions of the Post-test

At the end of the term, the author carried out another test to check whether, after the implementation of increasing the lexical chunks to English writing for one term, significant differences exists between the EC and CC. Again, their compositions were collected and marked and results were put into computer for systematic analysis. The results of SPSS are shown in the following tables.

TABLE2

POSTTEST ANALYSIS OF CLASS1 AND CLASS 2

\begin{tabular}{|l|l|l|l|l|l|}
\hline Group & Mean & $\mathrm{N}$ & Std. Deviation & Std. Error Mean & Sig. (2-tailed) \\
\hline CLASS1 & 70.4000 & 40 & 10.36958 & 1.63957 & \multirow{2}{*}{.039} \\
\hline CLASS2 & 75.0750 & 40 & 9.90050 & 1.56541 & \\
\hline
\end{tabular}

From the table above, it can be seen that the difference emerged in the students' posttest. In order to validate the test, with their S.D. as 10.36958 (experimental class) and 9.90050 (control class) respectively, the experimental class gets the mean of $75.0750,4.675$ points more than that (70.400) of the control class. From this table 2 above, it can be found that it was obvious that in the posttest both of the CC and EC groups have got the higher mean than that in the pretest, which means that both classes made progress in their writings. However, the students in the CC group improved not so much as the learners in the EC group. The students in EC, after a-term practice of English writing under the guidance of the lexical chunks teaching, improved the most by increasing 10.125 points. In the posttest, the mean scores in the experimental class are much higher than those of control class, which means that the latter improved a lot more than the former. The result shows that in the posttest, the performance of the test in experimental class is better than that in control class.

According to the T-test for comparison in posttest is shown in Table 2, there exist significant difference between CC and EC (the significance 0.039 is less than 0.05).Therefore, it can be concluded that there exists a significant difference between two groups.

This result proved the fact that the lexical chunk teaching and learning approach plays a positive role in improving the college students' English writing. This further proves that the experimental treatment play an important part in the improvement of writing performance of the experimental class. That is to say, the application of chunks helps to improve students' writing performance.

So we can make a conclusion that learners' writing proficiency can be improved by the application of Lexical Chunk Approach to EFL teaching.

According to the grading criteria of EFL writing, the scores should be marked based on the expressions of main elements, application of the vocabulary and grammatical structures to express the ideas accurately and appropriately. Therefore, the use of the vocabulary and phrases is fundamental to the marking of the writing. The application of Lexical Chunk Approach to EFL teaching helps to store the ready-made lexical units into the learners' mind, which benefits the appropriate language production for a particular situation.

In addition to the score analysis, the teachers pay more attention to the students' lexical use in their expressions. It is found that lexical chunks help students to use English fluently and properly. Besides, the input of lexical chunks as a whole can avoid errors resulting from vocabulary selection and cultural differences, thus improving the accuracy of language. With lexical chunks in mind, students can write more smoothly, which reduces their anxiety during the process of writing and increases their confidence. After the application of lexical chunk for one term, it is observed that students' EFL writing performance has improved a lot.

\section{CONCLuSiOnS AND SugGestions}

\section{A. Conclusion}

As is known, the goal of language teaching is not just to teach abstract language rules but also to get students to apply these rules to comprehending and producing language successfully in the proper context. Lexical chunks are frequently-occurred, fixed or semi-fixed multi-words or sentences formed by meanings rather than grammatical rules that are acquired as a whole automatically in the language acquisition, which thus are proved to be of great significant to the EFL learners.

Writing is a very important part of the learner's comprehensive English ability; therefore, much attention should be paid to English writing teaching and learning. This thesis aims at the application of lexical chunk input to non-English 
majors' writing.

This study investigated the effectiveness of lexical chunk input strategies in English writing. SPSS is used to analyze the results of the experiment.

As can be seen from the presented statistical analysis, Lexical chunks, the ready-made multi-word expressions, helps to store the ready-made lexical units into the learners' mind, which benefits the appropriate language production for a particular situation and reduce the lexical fossilization. In addition, lexical chunks as a whole can reduce errors resulting from vocabulary selection and thus can improve the accuracy of language. In all, the increase of lexical chunk input can reduce the negative transfer of the native language, thus improving their writing in terms of wording collocation, sentence building, discourse cohesion and expression and eventually help students to use English fluently and properly.

\section{B. Limitations and Suggestions for Future Research}

From the result of the study, we can see the importance of the lexical chunks approach in the better performance of the experimental class. Lexical chunks approach is helpful for both students and teachers in EFL writing learning and teaching. The present findings have some implications for both students and teachers.

Due to the limited time and the number of the subjects, there exist some defects in this study, and some suggestions can be made based on its limitations.

Firstly, the experimental research is of a small scale. The sample chosen for the experiment is not large enough. This study was conducted in Shandong Jiaotong University and there are only eighty participants who only came from the non-English majors in one university; and the students' levels vary from that of other universities, this might make the study a little unreliable. So the results can not be causally generalized or employed from one context to another. It is hoped that the future research will be based on more grades and majors, more universities with different English proficiency.

Secondly, due to the time limitation, the experiment only lasted for one term. If it had lasted a much longer period, three or four terms, the experiment results would be more persuasive and convincing. Therefore, future efforts should be made to plan a long study.

Lastly, the research focuses on the English writing, thus, marking of the students' essays may not be very objective. It is suggested that the future study should focus on the other aspects of English skills-reading, listening and vocabulary, which can be examined more objectively. It calls for teachers and researchers make more efforts and focus more attention on further research to find out an appropriate lexical chunks teaching approach so as to improve the students' foreign language acquisition.

The author is eager to see more and more research on the lexical chunks teaching approach employed to the learning and teaching of English. Thus, more and more researchers on lexical chunks can foresee a greater future and have more far-reaching influence on foreign language acquisition.

\section{REFERENCES}

[1] Becker, J. (1975). The phrasal lexicon. In Nash-Webber, B\&R. Schank (eds.). Theoretical Issues in Natural Language Processing. Cambridge, Masss: Bolt, Beranek \& Newman, 70-73.

[2] Lewis. M. (1993). The Lexical Approach: The State of ELT and the Way Forward. Hove, UK: Language Teaching Publications.

[3] Lewis. M. (1997). Pedagogical implications of the lexical approach in J. Coady, \& J. Hockin, (Eds). Second Language. Cambridge: Cambridge University Press, 1-10.

[4] Moon. (1997). Vocabulary connections: mufti-word item in English. In N. Schmitt and M. McCarthy (eds): Vocabulary, Description, Acquisition and Pedagogy. Cambridge: Cambridge University Press. 43

[5] Nattinger, J. \& J. Decarrico. (1992). Lexical Phrases Teaching. Oxford: Oxford University Press, and Language.

[6] Pawley, A. \& F. H. Syder. (1983). Two puzzles for linguistic theory native-like selection and native-like fluency. In Richards, J. C. and R. W. Schmidt (eds), Language and communication. London: Longman. 191-225.

[7] Duan Shiping. (2008). Review of the research on lexical chunks in second language teaching in China. Beijing: Journal of Foreign Languages In China. (4). 23-26

[8] Wu Jing, Wang Ruidong. (2002). Lexical chunks, English teaching resources to be exploited. Jinan: Shandong Foreign Language Teaching.

[9] Yao Baoliang. (2003). Prefabricated lexical chunks and English teaching. Shanghai: EnglishTeaching and Research Notes. 23 (3) -26.

[10] Yao Baoliang. (2004). Prefabricated lexical chunks and oral English teaching in the middle school. Beijing: Curriculum, Teaching Material and Method. 33 (4) - 38. 


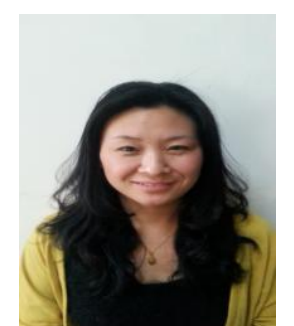

Qian Li was born in Baoding, Hebei province. The author graduated from Chongqing University in Chongqing, China in 2001 and gained the Bachelor's degree of Arts, majoring in English. In 2008, the author gained the Master's degree of Arts in Shandong Normal University.

She has been an English teacher from July of 2001 till now in Shandong Jiaotong University. In October of 2006, she gain the qualification of being an lecturer. During these years from 2001 to 2013 she has taken the foreign language teaching seminars organized by the foreign language teaching and research press for six times in the summer holidays. She has published 21 articles concerning foreign language teaching and researching in recents years. Some of the articles published are as the following: Oversears English, (Hefei, China, Anhui Science \& Technology Publishing House, 2010); Journal of Changchun University of Science and Technology, (Changchun, China, Editorial Board of Journal of Changchun University of Science and Technology, 2011); Time Education (Chengdu, China, Publishing Press of Time Education, 2010). Cross-cultural communication, teaching methods and the study of English as a foreign language are the current research interests of the author.

Ms. Li was the associate editor of Foreign Language Research and Practice which is published by Jilin University publishing press and was awarded "The Best Ten English Teachers of Shandong Province" in 2006. 